\title{
LITERATURA BRASILEIRA CONTEMPORÂNEA: CORRESPONDÊNCIAS ENTRE CÍNTIA MOSCOVICH E CLARICE LISPECTOR
}

\author{
EDUARDA CRISTINA LIMA (UFG) ${ }^{1}$ \\ LARISSA WARZOCHA FERNANDES CRUVINEL (UFG) ${ }^{2}$
}

\begin{abstract}
RESUMO: O objetivo deste estudo é pesquisar a relação que a contística da escritora brasileira contemporânea Cíntia Moscovich estabelece com a obra de Clarice Lispector. Para isso, será analisado o conto "O Telhado e o Violinista, de Arquitetura do arco-íris (2004), para observar como a autora trata as questões judaicas em sua obra e como é construído o diálogo que ela estabelece com o conto de Lispector, "Uma Galinha", de Laços de Família (2009). Dessa forma, o cotejo entre os contos das duas escritoras contribuirá para a compreensão das tendências estéticas da literatura brasileira contemporânea. Como fundamentação crítico-teórica, serão convocados os estudos de Erik Karl Schøllhammer (2011), Flávio Carneiro (2005), Paloma Vidal (2013), entre outros.
\end{abstract}

PALAVRAS-CHAVE: Literatura Brasileira Contemporânea. Cíntia Moscovich. Clarice Lispector.

ABSTRACT: The purpose of this study is to investigate the relation that the short stories by the contemporary brazilian writer Cintia Moscovich establish with Clarice Lispector's production. Therefore, the short story "O Telhado e o Violinista" from Arquitetura do arco-íris (2004), will be analyzed, intending to observe how the author deals with the jewish matters in her literary work and how the dialogue that she establishes with the short story of Clarice Lispector, "Uma Galinha" from Laços de Familia (2009), is built. Thus, the parallel between the production of these two writers will contribute to the understanding of the contemporary Brazilian literature's aesthetic tendencies. As critical-theorical foundation, the studies of Erik Karl Schøllhammer (2011), Flávio Carneiro (2005), Paloma Vidal (2013), among others, will be convened.

KEYWORDS: Contemporary Brazilian Literature. Cíntia Moscovich. Clarice Lispector.

\section{INTRODUÇÃO}

O objetivo deste estudo é compreender a contística de Cíntia Moscovich a partir da análise das questões judaicas representadas no conto "O Telhado e o Violinista", de Arquitetura do arco-íris (2004). Como a escritora porto-alegrense estabelece um intertexto entre o conto selecionado e o conto "Uma Galinha", de Laços de família (2009), de Clarice Lispector, procuraremos entender a ligação existente entre os referidos contos das duas autoras. Levando em consideração a ideia de tradição $^{3}$ e como ela se reflete na escrita de autores contemporâneos, entendemos que há certa intencionalidade na recuperação que o escritor faz quando retoma um texto anterior, como mostra Tânia Franco Carvalhal, em seu livro Literatura Comparada, quando reflete sobre os motivos de resgatar textos do passado:

Além disso, sabemos que a repetição (de um texto por outro, de um fragmento em um texto, etc. nunca é inocente.) [...] Toda repetição está carregada de uma

\footnotetext{
${ }_{1}^{1}$ Mestranda em Estudos Literários da Universidade Federal de Goiás. Programa de Pós-Graduação Letras e Linguística - Faculdade de Letras. E-mail: eduarrdalima@outlook.com

2 Doutora em Letras e Linguística pela Universidade Federal de Goiás com período sanduíche em École des Hautes Etudes en Sciences Sociales de Paris. Professora efetiva da Universidade Federal de Goiás. E-mail: larissacruvinel@hotmail.com

${ }^{3}$ Entende-se por tradição a genealogia de escritores que dialogam de maneiras distintas com o percurso literário de Clarice Lispector.
} 


\title{
$=$ TRAMA $=$
}

intencionalidade certa: quer dar continuidade ou quer modificar, quer subverter, enfim, quer atuar com relação ao texto antecessor (CARVALHAL, 2006, p.53).

A obra de Clarice Lispector apresenta a tendência de captar estados interiores, dando ênfase à subjetividade das personagens retratadas. Em vista disso, o tempo perde os contornos rígidos da lógica cronológica para operar uma sondagem das sensações mais recônditas do ser humano. Na esteira dessa tendência das obras clariceanas, os contos de Cíntia Moscovich buscam se aproximar de uma tradição intimista que, segundo Flávio Carneiro:

\begin{abstract}
tem forte respaldo em nossa tradição literária, começando timidamente a se manifestar no romantismo, ganhando consistência no século XIX e se afirmando de vez no século XX, com autores de peso como Graciliano Ramos, Lúcio Cardoso e Clarice Lispector, entre outros. Neste início de milênio, a vertente se reforça com Adriana Lunardi, Paloma Vidal, Ana Teresa Jardim, Cíntia Moscovich (CARNEIRO, 2005, p.307).
\end{abstract}

Dessa forma, Carneiro observa que a literatura brasileira contemporânea se volta frequentemente para a reescritura de textos do passado, operando uma releitura dos modelos de literatura modernos. Essa releitura apresenta uma consciência crítica em relação à obra de escritores já consagrados, o que confere um matiz próprio às novas narrativas que têm sido publicadas nas últimas décadas.

Karl Erik Schøllhammer (2011), em Ficção Brasileira Contemporânea, a partir dos estudos de Giorgio Agamben, considera que o "escritor contemporâneo parece estar motivado por uma grande urgência em se relacionar com a realidade histórica, estando consciente, entretanto, da impossibilidade de captá-la na sua especificidade atual, em seu presente."(SCHøLLHAMMER,2011,p.10). Dessa forma, a produção contemporânea não se molda apenas pelo presente em que está inserida, mas a partir de "uma estranheza histórica que a faz perceber as zonas marginais e obscuras do presente" (SCHøLLHAMMER, 2011, p.10). Portanto, o escritor contemporâneo é intempestivo e questiona seu próprio tempo, mesmo sabendo que há uma zona de sombra que não pode ser captada completamente.

Schøllhammer aponta também que a contemporaneidade apresenta, em meio a suas diversificadas tendências, o que ele chama de "literatura do eu", representada por escritores que constroem uma prosa mais existencial e intimista, na esteira da prosa de Clarice Lispector em alguns romances como A Paixão Segundo G.H. Nesse aspecto, a escrita de Cíntia Moscovich se aproxima da de Lispector, apesar de cada uma estar inserida em um cenário e em um momento diferente da literatura brasileira.

Paulo Roberto Tonani do Patrocínio (2013), em seu ensaio "Passageiro do fim do dia, de Rubens Figueiredo: Um olhar sobre o naturalismo",reflete sobre esse movimento de refacção operado pela literatura contemporânea quando propõe retomar temas e obras do passado, trazendo outras perspectivas que permitam uma maior compreensão de traços culturais e sociais do presente, como acontece na obra de Moscovich quando a escritora tematiza o judaísmo, ou sobre as relações interpessoais entre as personagens. Patrocínio aponta:

O movimento de acréscimo, [...] revela que estamos diante de algo que reproduz em diferença uma ação já realizada. Nesses termos, o novo não é explicitamente original, assim como o elemento que fora o objeto do resgate retorna com rasuras. Resulta desta construção um complexo jogo de percepções e interpretações que busca compreender os mecanismos sociais, políticos, culturais que tateiam o presente com os olhos voltados para o passado (PATROCíNIO, 2013, p.261).

Segundo Giorgio Agamben em O que é contemporâneo? E outros ensaios, ser contemporâneo implica em uma não completa aderência, a desacordo com seu próprio tempo. 


\title{
$=$ TRAMA $=$
}

A partir do conceito de intempestividade, de Friedrich Nietzsche, o filósofo vai construindo sua concepção acerca do assunto, refletindo sobre como os contrastes podem constituir sentidos complementares.

\begin{abstract}
A contemporaneidade, portanto, é uma singular relação com o próprio tempo, que adere a este e, ao mesmo tempo, dele toma distâncias; mais precisamente, essa é a relação com o tempo que a este adere através de uma dissociação e um anacronismo. Aqueles que coincidem muito plenamente com a época, que em todos os aspectos a esta aderem perfeitamente, não são contemporâneos porque, exatamente por isso, não conseguem vê-la, não podem manter fixo o olhar sobre ela (AGAMBEN, 2009, p. 59).
\end{abstract}

Dessa forma, Cíntia Moscovich, no conto selecionado para este estudo, ressignifica os temas, situações e personagens da obra de Lispector, fazendo uso do passado como forma de problematizar o presente. Por meio desse diálogo, é possível observar as tomadas de posição da escritora gaúcha, tanto do ponto de vista temático quanto formal, em relação a uma conhecida escritora da literatura brasileira que também era judia e se debruçou, mesmo que de forma mais velada, sobre questões judaicas.

Nesse sentido, esse estudo buscará compreender como se dá o diálogo entre o conto de Moscovich e de Lispector, tendo em vista principalmente a forma como a escritora portoalegrense ressignifica o conto da escritora ucraniana por meio de aspectos ligados ao judaísmo, como a perseguição sofrida pelos judeus.

\section{O TELHADO E O VIOLINISTA" E UMA GALINHA": A CONTEMPORANEIDADE VISITA O PASSADO}

Clarice Lispector teve sua primeira obra, Perto do coração selvagem, publicada em 1943. Muitas de suas obras foram traduzidas para diversas línguas como A Hora da Estrela (1977),sua última publicação em vida. Da mesma forma que Moscovich, muitas personagens de Clarice são mulheres, assim como as personagens dos contos que serão analisados adiante. As personagens clariceanas normalmente passam por situações em que uma nova ligação com o mundo se assenta, o que estabelece uma relação com a obra de Cíntia Moscovich, principalmente ao desnudar o comportamento da mulher em situações cotidianas envoltas por temas familiares.

Cíntia Moscovich publicou sua primeira obra, Reino das Cebolas, em 1996. Essa primeira publicação já recebeu relevo no panorama da literatura brasileira contemporânea ao ser indicada ao Prêmio Jabuti. Em 2006, com a publicação de Arquitetura do Arco-íris, ganhou o terceiro lugar na categoria de contos e crônicas desse renomado prêmio da literatura brasileira. Sua última publicação até então é o livro de contos Essa coisa brilhante que é a chuva?, de 2012. A autora aborda frequentemente as relações familiares em sua obra, mostrando como o dia-a-dia, aparentemente trivial, pode se oferecer como pano de fundo para os mais variados acontecimentos. As personagens principais de seus contos, em sua maioria mulheres, transgridem algumas normas oriundas de uma sociedade patriarcal, o que também pode ser observado na obra de Clarice Lispector.

O conto "A galinha", de Lispector, apresenta um acontecimento cotidiano: a fuga de uma galinha pelo telhado de uma casa de família. A narrativa tem início numa manhã de domingo, em que a cozinheira prepararia a galinha para o almoço. Porém, em um descuido da cozinheira, a galinha foge e é perseguida pelo dono da casa pelos telhados das casas vizinhas. A ave rompe sua aparente passividade para lutar por sua vida: "Pouco afeita a uma luta mais selvagem pela vida, a galinha tinha que decidir por si mesma os caminhos a tomar, sem nenhum 


\title{
$=$ TRAMA $=$
}

auxílio de sua raça". (LISPECTOR, 2009, p.30) No momento da perseguição, é perceptível como o animal é tratado como algo substituível, como se não fosse um ser:

\begin{abstract}
"Estúpida, tímida e livre. Não vitoriosa como seria um galo em fuga. Que é que havia nas suas vísceras que fazia dela um ser? A galinha é um ser. É verdade que não se poderia contar com ela para nada. Nem ela própria contava consigo, como o galo crê na sua crista.Sua única vantagem é que havia tantas galinhas que morrendo uma surgiria no mesmo instante outra tão igual como se fora a mesma" (LISPECTOR, 1960, p.31).
\end{abstract}

Contudo, a galinha apresenta características humanas: "Sozinha no mundo, sem pai nem mãe, ela corria, arfava, muda, concentrada." (LISPECTOR, 1960, p.31). O dono da casa age com certa indiferença em relação à busca de liberdade da ave. Para ele caçar a galinha e prendê-la é como um esporte domingueiro. Apesar de tentar a todo custo fugir, a galinha é capturada com violência: "Entre gritos e penas, ela foi presa. Em seguida carregada em triunfo por uma asa através das telhas e pousada no chão da cozinha com certa violência, mas ao chegar em casa, ela bota um ovo." (LISPECTOR, 2009, p.31). Para Lúcia Galeti, em sua dissertação de mestrado intitulada "O bestiário de Clarice Lispector", há um movimento duplo no conto clariceano:

\begin{abstract}
Esse movimento duplo parece se configurar em razão de o itinerário percorrido pela galinha se dar em duas instâncias semânticas. Inicialmente, temos uma galinha que o narrador nos informa que é 'uma galinha de domingo' e que só estava viva porque não passava de nove horas da manhã mas que, fatalmente, por isso, quando chegasse a hora, cumpriria o destino reservado a todas as galinhas, ser devorada pelos seres humanos. Entretanto, antes que isso acontecesse, a galinha tenta libertar-se deste seu destino implacável empreendendo uma fuga cujo itinerário é duvidoso e incerto. Será na tentativa de fuga da galinha que a família se verá forçada a segui-la a fim de recuperá-la. Nesse processo de seguir o itinerário da galinha em fuga, a família e seus membros são impelidos ao questionamento dos próprios itinerários, ou melhor dizendo, ao questionamento dos próprios comportamentos e das relações sociais/afetivas que os sustentam (GALETI, 2001, p.44-45).
\end{abstract}

Segundo Galeti, quando a galinha sai da situação de comodidade e foge para lutar por sua vida, a família também é obrigada a repensar os seus padrões de comportamento e a refletir sobre o sentido da existência. A menina da família, admirada com o fato de a galinha ter botado um ovo, exalta-se e pede para que a mãe não mate a galinha, já que agora ela pôs um ovo e assim começa a ser tratada com o cuidado que a maternidade, na sua ótica, exigiria:

Inconsciente da vida que the fora entregue, a galinha passou a morar com a família. A menina, de volta do colégio, jogava a pasta longe sem interromper a corrida para a cozinha. O pai de em quando ainda se lembrava: "E dizer que eu a obriguei a correr naquele estado". A galinha tornara-se a rainha da casa (LISPECTOR, 2009, p.32).

O tempo se passou, o conto caminha para o fim mostrando que tanto a ignorância da galinha quanto ao seu destino continuava a mesma, "na fuga, no descanso, quando deu à luz ou bicando milho - era uma cabeça de galinha, a mesma que fora desenhada no começo dos séculos" (LISPECTOR, 2009, p.33). No conto de Lispector a galinha se aproxima metaforicamente da mulher, que sofre com as pressões sociais impostas por uma visão patriarcal, além da violência também metaforizada por sua captura. Sobre isso, Silviana Kelly Gomes de Oliveira e Olavo Barreto de Souza consideram: 


\section{$=$ TRAMA $=$}

A personagem galinha aqui se apresenta dentro de uma perspectiva que tanto pode ser graças à cultura em que vivemos, a qual adota o costume de ter o animal como alimento, passando pelo processo de matá-lo em casa, quanto à imagem da mulher dentro da sociedade patriarcal, cujo comportamento se delineia sob o viés da predominância masculina sobre a mulher, submetida, por vezes, à violência e renegada dos seus direitos de liberdade individual (OLIVEIRA e SOUZA, 2014, p.9).

Assim, o conto, em sua multiplicidade de sentidos, abre-se tanto para uma leitura ligada à representação das pressões patriarcais impostas às mulheres, na vertente da crítica de autoria feminina, quanto pode ser vista como "objeto de representação daquilo que é frágil, miserável, desprezível, mas também daquilo que se torna livre e, por isso, fascina e encanta as relações humanas que a ele se acham diretamente atreladas" (GALETI, 2001, p.46.)

A construção do conto "O telhado e o violinista", de Cíntia Moscovich, estabelece um diálogo com "A galinha", de Lispector, em vários aspectos. Já de início, embora o foco narrativo seja em primeira pessoa no primeiro e em terceira pessoa no segundo conto, há um olhar voltado para personagens femininas. Em ambos os contos, uma menina, ainda criança, que mora com sua família, evita que uma galinha seja morta para ser servida em uma refeição familiar.

Foi aí que aconteceu: a galinha me olhou. Um olho de esperança, como se eu tivesse algum poder messiânico. E as pupilas pretas da galinha, com um espanto de cera preso nas pálpebras amendoadas, pediam qualquer gesto redentor da criança que eu era. Amor de salvação era coisa de adultos. Mas houve um momento em que a bondade me ultrapassou, porque um dia eu seria mãe, e porque era filha e neta e irmã e sobrinha. Acocorada, repeti os mimosinhos e afaguei a crista sangüínea e tenra, a galinha deixando-se acariciar como se fosse um gato ou um cachorro. Como se não fosse uma galinha. Alguma coisa, em mim e nela, acontecia, algo que eu não chegava a entender a olho nu. Sei hoje que a galinha foi acometida de uma esperança difícil e torta, mas ainda assim esperança (MOSCOVICH, 2004, p.23).

O conto de Moscovich é narrado por uma narradora adulta, casada, mãe de uma filha pequena, que relata um episódio de sua infância, de quando tinha 9 anos, e sente as dores de ser agredida por ser judia. Após ser chamada de "judia suja", frase impactante que dá início ao conto, ela vai até a avó contar o que ocorreu. Aqui já é possível perceber o cenário construído por Moscovich: uma situação do dia-a-dia familiar, em que se insere uma circunstância impactante como a intolerância religiosa. Nesse quadro, após a avó contar à família a situação pela qual a menina havia passado, sendo atacada por uma vizinha também criança - Paula -, a mãe e o pai mostram sua revolta e a família começa a reviver sentimentos há muito tempo guardados ligados à perseguição aos judeus.

O pai espalmou as duas mãos sobre a madeira da mesa, os olhos ferviam de ultraje. Voltou a lembrar daquela história que era nosso horror ancestral: o ódio, as perseguições, os mortos a troco de nada e - horror entre os horrores - a casa e a família da avó arrasadas num progom, daqueles com cossacos em seus cavalos. Nossa velhinha emitiu mais um suspiro, os olhos se perderam em novas cintilações azuis. O pai deu um jeito solene à voz: - Daqui por diante, que nenhum de nós volte a falar com aquela mocinha anti-semita - e punha-se bem em seu papel de patriarca. Olhando para mim, agora com ternura de aprovação, ele acariciou a minha franja e a da minha boneca: - Você fez bem em chamar aquela burra de burra. Nada de humilhações e de vergonha (MOSCOVICH, 2004, p.21).

Toda essa primeira situação vivida pela família judia cria, segundo Berta Waldman, "a oportunidade para sua avó e os pais tratarem de pogroms, do Holocausto, do antissemitismo, 


\title{
$=$ TRAMA $=$
}

da história de perseguições a que foram constrangidos eles, em particular, e os judeus, em geral." (WALDMAN, 2016, p.2)

Após esse episódio, a avó traz uma galinha viva para o espaço onde a família mora para servi-la no jantar. Quando ela está prestes a prepará-la para o jantar, a menina pensa que se a avó matasse a galinha ela seria "indiferente ao terror" (MOSCOVICH, 2004, p.22). Um terror tão vivo ainda em suas histórias sobre sua própria família judia. Depois dessa reflexão, a menina convence a avó a não matar a galinha, que é salva devido a essa intervenção e recebe o nome de Hortênsia. Há uma descrição do jantar de Yom Kippur - o Dia do Perdão, uma das datas mais importantes para o judaísmo em que fazem um jejum de 24 horas e orações intensas trazendo à tona a tradição e a cultura judaica por meio da comida e da tradição religiosa:

\begin{abstract}
No jantar de Yom Kipur, a mesa era mais do que matar a fome: tivemos beigales de batatas que estouravam em crostas tostadas, knishes de ricota fofos na textura de gordura e farinha, saladas de mangas e melões nadando em espesso creme agridoce, torta de berinjelas e cebolas que cintilavam à luz do castiçal de prata. O chrein, na energia colorida das beterrabas, acompanhava os bolinhos de peixe: comemos guefiltefish ensopado com tiras de cenouras, pimentões e tomates. Estávamos pacificados pela fartura, esperançosos pelo ano que se iniciava, mas mesmo assim meus irmãos reclamaram. Foi o primeiro Yom Kipur em que não houve disputa pelas coxas de galinha. Uma vez que galinha não havia (MOSCOVICH, 2004, p.24).
\end{abstract}

Naquela madrugada, a família tem uma surpresa: Hortênsia havia botado um ovo. A partir desse momento, os sentimentos de felicitações à maternidade tomam conta dos membros do clã, que passam a cuidar da ave que poderia gerar uma vida. A menina atribui à galinha sentimentos humanos: "De vez em quando, piscava os olhos lentamente: eu podia jurar que ela pensava." (MOSCOVICH, 2004, p.26). Quando o ovo finalmente é chocado, a menina deu ao pintinho que nasceu o nome de Fúlvio e o ato de nomeá-lo aproxima cada vez mais a galinha e o filhote dos laços familiares que ali se formavam.

Mais adiante na narrativa, Paula entra em cena novamente, trazendo à tona mais uma vez a desordem e a ameaça à casa da família judia por colocar em pauta outra vez o preconceito antes professado contra a menina e suas origens: "Todos estacamos, aparvalhados com a cena: segurando a vassoura, a avó tinha os olhos cintilantes de ódio, as veias do pescoço inundadas de fúria mosaica - Paula tinha virado um cossaco" (MOSCOVICH, 2004, p.33).

Waldman aponta que a avó no conto de Moscovich representa a tradição familiar judaica, visto que ela ensina à família sobre suas origens:

A avó é uma remanescente dos judeus vindos do shtetl, primeira geração de imigrantes. É falante do ídiche, idioma que permeia a narrativa, coagulado em expressões, frases feitas, aforismos: oi, veis is mir, mishigine, mazel tov; em comidas: beigales, guefilte fish, chrein. É a detentora da tradição familiar, o que se nota no empenho em transmitir para a neta as histórias de cossacos com sabres em seus cavalos, acuando os judeus, vivenciadas por ela em sua terra de origem (WALDMAN, 2016, p.3).

Portanto, há no conto a representação da tradição, passada de geração para geração, encarnada principalmente pela figura da avó. Enquanto a avó vivenciou a história dos cossacos e da violência contra os judeus, os pais, e principalmente a filha, vivenciam essas lembranças na forma do preconceito ainda sofrido em ações como as de Paula no conto.

Com um pedido de desculpas como pretexto, Paula pede para ver o pintinho. A menina a deixa esperando e vai perguntar ao pai como deve proceder. Ao deixá-la sozinha, Paula entra no apartamento, pega Fúlvio nas mãos e, mesmo com todos os membros da família tentando 


\section{$=$ TRAMA $=$}

fazer com que ela solte a pequena ave, o pinto é muito frágil e morre em suas mãos. Com a morte do pinto, as pessoas são tomadas de grande tristeza e o luto se instala na casa.

O conto termina com a narradora, agora adulta, à mesa com sua família. Sua filha havia trazido um pintinho para casa e ela conta que também teve um no passado e que ele havia morrido pelas mãos de uma menina má. Apesar de reavivada a memória, ela se vê impedida de contar das motivações de Paula, e principalmente narrar assuntos que trariam dor e tristeza, como o holocausto, por exemplo.

A família judia não é indiferente a um pinto que, apesar de ser um animal, é tratado como um ser que tem direito à vida. A dor da família pela violência praticada por Paula é amenizada com o tempo, embora esteja sempre presente, como na última cena do conto em que a narradora, já adulta, relembra a situação passada, porém, ainda assim, protegendo a filha das histórias sobre as perseguições aos judeus.

Na hora da janta, apesar da contrariedade do meu marido, o pintinho foi colocado para nos fazer companhia. Contei a Flávia que eu também tive um pintinho quando era criança e que ele havia sido morto por uma menina muito má. Minha filha, apavorada, quis saber:

- Por quê? Olhei o pinto: parecia-se à gema que havia sido, trêmulo de infância. Olhei meu marido, olhei minha filha: eles esperavam a resposta que ia salvar a família e a humanidade. - Sei lá - quis ganhar tempo. E já ia falar algo sobre pogroms, holocaustos e pescoços quebrados, quando fui interrompida por um longo - tão longo - piar do pinto (MOSCOVICH, 2004, p.26).

Segundo Matos (2010), "Cíntia Moscovich particulariza sua escrita através de epifanias e de experiências de um mundo coberto de sortidas reflexões, de fartos amores, de impasses paralisantes, de vozes rascantes da memória" (MATOS, 2010, p.122). O conto de Moscovich dá ênfase às passagens relacionadas à violência contra os judeus, que persiste no presente, mesmo depois da divulgação dos horrores do holocausto. Quando Paula mata o pinto é como se tivesse matado um membro da família, retomando a agressão histórica sofrida pelos judeus.

Dessa forma, Moscovich acrescenta outros matizes ao conto "Uma galinha", de Lispector. O conto clariceano acena de forma sutil para a perseguição sofrida pela galinha e para a mudança de olhar da família em relação à ave. A escritora gaúcha parte dessas aberturas do conto da escritora ucraniana para dar ênfase à intolerância religiosa, trazendo a tona questões do judaísmo. Ambas as autoras tocam em pontos delicados, como a construção da imagem da mulher na sociedade patriarcal e a sobrevivência da agressão aos judeus, incitando o leitor a alargar o olhar para novos os sentidos proporcionados pelo diálogo intertextual.

Karl Erik Schøllhammer, em seu já referido estudo, defende a existência de uma polarização de duas estéticas literárias na contemporaneidade. Por um lado, há uma leva de escritores que buscam retratar a realidade da sociedade brasileira, apresentando uma escrita áspera sobre a violência das cidades. Por outro lado, há uma outra tendência centrada em um realismo mais íntimo e familiar, mais aos moldes de Cíntia Moscovich: "De um lado, haveria a brutalidade do realismo marginal, que assume seu desgarramento contemporâneo, e, de outro, a graça dos universos íntimos e sensíveis, que apostam na procura da epifania e na pequena história inspirada pelo mais dia, menos dia de cada um" (SCHøLLHAMMER, 2009, p.15).

Moscovich, na esteira dessa tendência mais íntima, retoma o passado sem negá-lo de forma categórica. É como se a autora fizesse uma releitura do conto de uma conhecida escritora brasileira para acrescentar outros sentidos além dos que foram conferidos ao texto primeiro. Acerca disso, Flávio Carneiro, ao comentar o romance histórico Em Liberdade (1981), de Silviano Santiago, considera o autor resgata aspectos da obra de Graciliano Ramos, realizando uma suplementação do moderno pelo pós-moderno e não a negação dele: 


\section{$=$ TRAMA $=$}

Silviano coloca na ficção sua concepção teórica de que o pós-moderno não é a negação mas a suplementação do moderno, entendendo por suplemento, via conceituação de Derrida, algo que se acrescenta àquilo que já é um todo. Não se trata, portanto, de levantar bandeiras contra adversários, estéticos ou políticos, mas de reescrever o passado, buscando acrescentar-lhe o que pode haver de novidade, de inovação, no âmbito do presente (CARNEIRO, 2005, p.26).

Assim como Santiago, Moscovich apela para a reescriturado passado por meio da retomada do conto de Clarice Lispector. A escritora gaúcha acrescenta outras leituras ao conto "Uma galinha", ampliando as formas de se ler a prosa clariceana na contemporaneidade.

\section{CONSIDERAÇÕES FINAIS}

O diálogo entre o conto "O telhado e o violinista", de Cíntia Moscovich, com o conto "Uma galinha", de Clarice Lispector, mostra como textos da literatura brasileira contemporânea retomam textos do passado para ampliar suas formas de leitura. Percebemos, dessa forma, que o conto de Moscovich aqui analisado apresenta a tendência de reescrever a obra de escritores consagrados da tradição literária brasileira para problematizar questões ainda prementes no presente, como a intolerância religiosa contra os judeus.

Dessa forma, o conto de Moscovich recupera vários aspectos do enredo do conto de Lispector, como a presença da galinha que vai ser servida em uma refeição familiar. Nos dois contos, o modo de pensar da família sofre uma alteração e seus membros passam a enxergar a ave como um ser vivo, em muitos momentos com características humanas. Contudo, a escritora gaúcha parte de motivos presentes no conto anterior, como a violência e a perseguição à galinha, assim como a posterior receptividade a um animal, que, apesar de não ser da família, passa a ocupar um lugar no clã, para dar maior ênfase à perseguição que os judeus sofreram e sofrem devido à intolerância religiosa.

Nesse sentido, o conto de Moscovich não estabelece uma negação dos modelos do passado. Pelo contrário, a autora, além de problematizar o presente, potencializa leituras aparentemente insuspeitas do conto clariceano, lançando luzes também sobre outras formas de leitura da obra de escritores consagrados da literatura brasileira na contemporaneidade.

\section{REFERÊNCIAS}

AGAMBEN, Giorgio. O que é o contemporâneo? e outros ensaios. Trad.: Vinicius Nicastro Honesko. Chapecó, SC: Argos, 2009.

CARNEIRO, Flávio. No País do Presente: Ficção brasileira no início do século XXI. 1 ed. Rio de Janeiro:

Rocco, 2005.

CARVALHAL, Tânia Franco. Literatura Comparada. 4 ed. São Paulo: Ática, 2006.

DALCASTAGNĖ, Regina (Org). Ver e Imaginar o outro: Alteridade, desigualdade, violência na literatura brasileira contemporânea. São Paulo: Horizonte, 2008.

GALETI, Lúcia. O bestiário de Clarice Lispector. 2001.85f. Dissertação (Mestrado em Literatura) - Curso de Pós-Graduação em Letras do Setor de Ciências Humanas, Letras e Artes da Universidade Federal do Paraná, Curitiba, 2001.

LISPECTOR, Clarice. Laços de Família. Rio de Janeiro: Rocco, 1960.

MATOS, Ana Lígia. Paisagem portátil. e-scrita - Revista do Curso de Letras - INIABEU, Nilópolis, v. 1, Número 1, Jan.-Abr. 2010

MATTÉ, Manuela. Relações intertextuais em Clarice Lispector e Cíntia Moscovich. Revista Línguas \& Letras Unioeste - Vol. 15 - No 30 - Segundo Semestre de 2014.

MOSCOVICH, Cíntia. Arquitetura do arco-íris. Rio de Janeiro: Record, 2004.

OLIVEIRA, Silvanna Kelly Gomes de; Souza, Olavo Barreto de. As galinhas de Clarice: Um estudo sobre a representação da personagem "galinha" nos contos "O ovo e a galinha", "Uma galinha" e "Uma história de tanto amor”. In:V ENLIJE, 2014, Campina Grandxe. Anais Enlije V. Campina Grande: Editora Realiza, 2014 (v.01). 
PADILHA, Elaine Pereira Andreatta. Memória, influência e superação na prosa de Cíntia Moscovich.127f. Mestrado em Letras — Universidade Federal do Amazonas, Manaus Biblioteca Depositária: Setorial ICHL, 2013.

SCHØLLHAMMER, Karl Erik. Ficção brasileira contemporânea. 2 ed. Rio de Janeiro: Civilização Brasileira, 2011.

VIEIRA. Nelson H. A Expressão judaica na obra de Clarice Lispector. Rio Grande do Sul. Zero Hora, 1988. WALDMAN, Berta.Comida, família e escritura na ficção de Cíntia Moscovich. Arquivo Maaravi: Revista Digital de Estudos Judaicos da UFMG. Belo Horizonte, 2016.

.Por linhas tortas: o judaísmo em Clarice Lispector. Arquivo Maaravi: Revista Digital de Estudos Judaicos da UFMG, Belo Horizonte, 2011.

Recebido em 10-05-2019 Aceito em 26-09-2019 